\title{
Direct sample introduction GC-MS/MS for quantification of organic chemicals in mammalian tissues and blood extracted with polymers without clean-up
}

\author{
Andreas Baumer ${ }^{1}$ (D) Beate I. Escher ${ }^{1,2} \cdot$ Julia Landmann $^{3} \cdot$ Nadin Ulrich $^{4}$ \\ Received: 7 May 2020 / Revised: 27 June 2020 / Accepted: 5 August 2020 / Published online: 15 August 2020 \\ (C) The Author(s) 2020
}

\begin{abstract}
Solvent extracts of mammalian tissues and blood contain a large amount of co-extracted matrix components, in particular lipids, which can adversely affect instrumental analysis. Clean-up typically degrades non-persistent chemicals. Alternatively, passive sampling with the polymer polydimethylsiloxane (PDMS) has been used for a comprehensive extraction from tissue without altering the mixture composition. Despite a smaller fraction of matrix being co-extracted by PDMS than by solvent extraction, direct analysis of PDMS extracts was only possible with direct sample introduction (DSI) GC-MS/MS, which prevented coextracted matrix components entering the system. Limits of quantitation (LOQ) ranged from 4 to $20 \mathrm{pg} \mu \mathrm{L}^{-1}$ ethyl acetate (PDMS extract) for pesticides and persistent organic pollutants (POPs). The group of organophosphorus flame retardants showed higher LOQs up to $107 \mathrm{pg} \mu \mathrm{L}^{-1}$ due to sorption to active sites at the injection system. Intraday precision ranged between 1 and $10 \%$, while the range of interday precision was between 1 and $18 \%$ depending on the analyte. The method was developed using pork liver, brain, and fat as well as blood and was then applied to analyze human post-mortem tissues where polychlorinated biphenyls (PCBs) as well as dichlorodiphenyltrichloroethane (DDT) and DDT metabolites were detected.
\end{abstract}

Keywords Mammalian tissues · Direct sample introduction GC-MS/MS · Passive sampling · PDMS · Co-extracted matrix · Reduction of matrix effects

\section{Introduction}

Organisms are exposed to a variety of chemicals that are present in environmental matrices like air, water, and soil. Especially hydrophobic organic chemicals (HOCs) tend to

Electronic supplementary material The online version of this article (https://doi.org/10.1007/s00216-020-02864-6) contains supplementary material, which is available to authorized users.

Andreas Baumer

andreas.baumer@ufz.de

1 Department Cell Toxicology, Helmholtz Centre for Environmental Research-UFZ, 04318 Leipzig, Germany

2 Environmental Toxicology, Centre for Applied Geoscience, Eberhard Karls University Tübingen, 72074 Tübingen, Germany

3 Institute of Anatomy, University of Leipzig, 04103 Leipzig, Germany

4 Department Analytical Environmental Chemistry, Helmholtz Centre for Environmental Research-UFZ, 04318 Leipzig, Germany bioaccumulate via food webs in biota tissues due to their high lipid solubility and persistence against degradation [1]. One example of HOCs are persistent organic pollutants (POPs) like polychlorinated biphenyls (PCBs) or organochlorine pesticides (OCPs) which have been measured in biota samples from the aquatic environment [2], bird eggs [3], polar bears [4], and in human tissues like liver, kidney, brain, and adipose tissue [5-7]. Since human tissues are generally not easily accessible for the analysis of POP concentrations, blood is often used as sample matrix for the investigation of human exposure [8]. As exposure of humans to POPs has decreased due to restrictions in the last decades, biomonitoring studies are now focusing on other bioaccumulative compounds like flame retardants, plasticizers, environmental phenols, or fungicides [9]. These compounds are not as persistent as POPs and hence have lower bioaccumulation factors, but the elimination from specimens can still require weeks up to months [9].

Most analyses of biological tissues have been carried out using solvent extraction methods followed by various cleanup procedures in order to reduce the amount of co-extracted 
matrix components prior to GC-MS measurements [10-12]. These extractions have a high solvent consumption as well as often time-consuming and labor-intensive purification steps of sample extracts. Most of the applied clean-up procedures degrade non-persistent contaminants. Equilibrium passive sampling with polydimethylsiloxane (PDMS) can be applied to complex biota matrices [13] without altering the mixture composition, including all HOCs $[14,15]$. This extraction method was applied to the analysis of environmental contaminants in various complex biota matrices, e.g., fish [13, 16, 17], eel [18], blubber [19, 20], blood plasma [21], urine [22], and whole blood $[22,23]$. HOCs are selectively taken up by the PDMS, because only uncharged molecules are able to diffuse into the polymer, whereas the uptake of proteins, salts, or metals is hindered [23]. Thus, equilibrium passive sampling with PDMS results in less co-extracted material compared to raw extracts of traditional solvent extraction methods. In case of dugong blubber with a lipid content of $85 \%(w / w)$, only approximately $4 \mathrm{mg}$ lipids per g PDMS were coextracted from $500 \mathrm{mg}$ tissue (corresponding to $0.8 \%$ of co-extracted lipids) at equilibrium [19, 24]. Another study investigated the partitioning of POPs between PDMS and pure oils and reported an average co-extracted amount of lipids of $0.9 \%$ [25].

Even this small amount of co-extracted lipids can contaminate sensitive analytical instruments, such as GC-MS systems. Using solvent injection techniques employing split/ splitless (SSL) injectors, non-volatile co-extracted matrix components (e.g., triglycerides) can build up in the injection port and at the front of the capillary column generating active sites which leads to peak broadening or peak tailing, loss of sensitivity, and matrix-induced peak enhancement, also known as matrix effects [26, 27]. Analytical results are severely affected and time-intensive maintenance of the GC system and ion source has to be conducted. Although sample extracts contain only small amount of co-extracted matrix, there is still a need of extract purification, typically by the addition of sulfuric acid in order to digest lipids followed by further treatment using a Florisilß column with drying agents for elimination of water [13, 19, 23, 28]. If POPs like PCBs are analyzed, which are not degraded by the treatment with sulfuric acid, no severe loss of these analytes occurs [28]. If the analysis includes $\mathrm{pH}$ labile analytes, other non-aggressive cleanup procedures like gel permeation chromatography (GPC) [29-31], solid-phase extraction (SPE) [31-33], dispersive solid-phase extraction (dSPE) [34-36], or low temperature precipitation (freeze out of lipids) [36-38] are employed either as single clean-up step or in combination.

Analysis of raw sample extracts using GC circumventing the clean-up steps mentioned above can be conducted by the principle of direct sample introduction (DSI), which was reported by Amirav and Dagan [39], and is also known as difficult matrix injection (DMI). Briefly, raw extracts obtained from solvent extractions, liquid samples like urine and oil, or even solid samples are placed in disposable micro vials ( $\mu$ vials), which are introduced to the programmable temperature vaporizing (PTV) injector at low temperatures. After heating to a temperature required for evaporation of the (semi-) volatile analytes, the non-volatile matrix components remain inside the $\mu$-vial, whereas the analytes are refocused on front of the cold analytical column. The $\mu$-vial with the remaining matrix is exchanged during chromatographic separation resulting in less GC system maintenance and analytical interferences. The DSI approach was evaluated in different matrices like fruits [40-42], vegetables [42, 43], cereals [42, 44], eggs [45], and oils [46, 47].

The aim of our work was to develop an analytical method for liver, brain, and adipose tissue as well as for whole blood and to investigate the chemical burden of human tissues and blood. We selected 27 chemicals including PCB congeners, DDT and its metabolites dichlorodiphenyldichloroethane (DDD) and dichlorodiphenyldichloroethylene (DDE), pesticides like atrazine (ATZ), metolachlor (MTC), and chlorpyrifos-methyl (CPM) as well as organophosphorus flame retardants like triphenyl phosphate (TPP) and tris(2chloroethyl) phosphate (TCEP). To achieve this aim, we combined the equilibrium passive sampling with PDMS and the DSI approach employing thermodesorption to provide a method for unbiased analysis of PDMS extracts with an application to pork and human tissues covering a broad range of persistent and non-persistent hydrophobic chemicals with different functional groups and physicochemical properties.

Typically, the analysis of the analytes extracted with PDMS is carried out by direct thermodesorption of the silicone sampler. Although the direct analysis saves time, the analysis of the corresponding solvent extract has advantages because it allows multiple detection methods, such as different ionization modes in GC or analysis with liquid chromatography. Furthermore, repeated analysis of the same sample is possible (e.g., in case of instrumental error). Importantly, for future studies, the chemical analysis can be combined with toxicological screening using in vitro bioassays [48]. To allow parallel application of analytical and bioanalytical methods, we applied higher volumes of PDMS, which also allows higher enrichment of the samples because the partition coefficients between tissue and PDMS are low [25] and will not enrich chemicals of low concentration sufficiently for detection.

\section{Experimental section}

\section{Chemicals}

Chemicals included in this study with their CAS number, abbreviation, purity, and supplier can be found in the 
Electronic Supplementary Material (ESM, Section S1, Table S1). For the determination of total lipid content of biota samples, 1-palmitoyl-2-oleoyl-sn-glycero-3-phosphocholine (POPC, Avanti Polar, Alabaster, AL, USA) and triolein (Sigma-Aldrich, Taufkirchen, Germany) were used as standards. Bovine serum albumin (BSA) (Sigma-Aldrich, Taufkirchen, Germany) was used as negative control. Ethyl acetate (EA), dichloromethane (DCM), and methanol $(\mathrm{MeOH})$ were purchased in $\mathrm{GC}$ grade and cyclohexane $(\mathrm{CH})$ and isopropanol (IPA) were purchased in LC grade, all from Merck (Darmstadt, Germany). Polydimethylsiloxane (PDMS, SSP-M823, Special Silicone Products, Ballston, USA) sheets (approximately $30 \mathrm{~cm} \times 30 \mathrm{~cm}$ ) with thicknesses of $1 \mathrm{~mm}$, $0.6 \mathrm{~mm}$, and $0.3 \mathrm{~mm}$, and a density of $1.17 \mathrm{~g} \mathrm{~cm}^{-3}$ were provided by Shielding Solutions (Great Notley, Great Britain).

\section{Tissue and blood samples}

Pork liver, brain, and fat were bought at a local butchery. Whole blood from pig (containing $1.5 \mathrm{mg}$ ethylenediaminetetraacetic acid dipotassium salt $\left(\mathrm{K}_{2}\right.$ EDTA) per $\mathrm{mL}$ whole blood) was obtained from Fiebig-Nährstofftechnik (FiebigNährstofftechnik GbR, Idstein-Niederauroff, Germany).

Human post-mortem liver, brain, blood, and (abdominal) adipose tissue were obtained from one body donor. Being part of the body donor program regulated by the Saxonian Death and Funeral Act of 1994 (third section, paragraph 18 item 8), institutional approval for the use of the post-mortem tissues of human body donors was obtained from the Institute of Anatomy, University of Leipzig. All authors declare that all experiments were conducted according to the principles of the Declaration of Helsinki [49]. Blood from a volunteer (29 years, male) was collected under medical supervision, stored in a commercially available blood donation tube containing $\mathrm{K}_{2}$ EDTA as anticoagulant yielding a final concentration of $1.8 \mathrm{mg} \mathrm{K}_{2}$ EDTA per $\mathrm{mL}$ whole blood (BD Vacutainer, BD Diagnostics, Heidelberg, Germany). Blood samples obtained from the body donor showed coagulation and progressive hemolysis and could not be used for the analysis. All tissues were homogenized using a blender (B-400, BÜCHI Labortechnik AG, Switzerland). Homogenized tissues as well as whole blood samples were stored at $-20{ }^{\circ} \mathrm{C}$ until analysis.

\section{Determination of total lipid content}

Determination of total lipids was carried out gravimetrically after solvent extraction according to Smedes [50] with modifications for the use of small amounts of tissues ( 50 to $500 \mathrm{mg}$ ) outlined in the ESM (Section S2).

\section{Preparation of PDMS}

PDMS was cleaned by Soxhlet extraction with EA for the duration of $24 \mathrm{~h}$ in order to remove residual impurities and monomers. Cleaned PDMS was stored in brown DURAN® bottles covered with fresh EA until usage at room temperature. Before immersion into tissue or blood, PDMS was air-dried for at least $2 \mathrm{~h}$ to ensure complete evaporation of remaining EA.

\section{Passive sampling of tissues and blood}

A microbalance was used to determine the initial mass of airdried PDMS in order to monitor the mass gain after passive sampling was completed. Pre-weighted PDMS (approximately $125-400 \mathrm{mg}$ ) was carefully immersed into the homogenized tissues or blood. The PDMS weights were tracked individually through all experiments. Equilibrium in passive sampling with PDMS was attained even for analytes with slow uptake kinetics after $168 \mathrm{~h}$ for all matrices and was assessed either with time series experiments or with silicone of multiple thicknesses [13] (data not shown). All passive sampling experiments were carried out at $4-8{ }^{\circ} \mathrm{C}$ to slow down tissue decay during sampling time.

Three different experimental set-ups depending on the lipid content of the sample were carried out in order to reach equilibrium. (1) Static sampling experiments for fat tissue was carried out with PDMS of $1 \mathrm{~mm}$ thickness, which was cut in circular discs with a diameter of $12 \mathrm{~mm}$ yielding a weight of approximately $125 \mathrm{mg}$ PDMS per disc. The PDMS disc was sandwiched between two tissue layers, which consisted of $200 \mathrm{mg}$ adipose tissue each. (2) Dynamic sampling experiments for liver and brain tissue were performed with $3 \mathrm{~g}$ homogenized tissue in $4 \mathrm{~mL}$ vials employing silicone strips of approximately $330 \mathrm{mg}$ PDMS $(55 \times 5 \times 1 \mathrm{~mm})$, which served as stirrer and sampler simultaneously avoiding sample depletion occurring during passive sampling of lean tissues [13]. (3) For blood, $2 \mathrm{~mL}$ were extracted with approximately $400 \mathrm{mg}$ PDMS $(60 \times 10 \times 0.6 \mathrm{~mm})$. The PDMS strips were fixed in a 4 $\mathrm{mL}$ vial that was sealed with a cap containing a PTFE septum after the blood sample was added. For extraction, the vial was placed on a roller mixer with a speed of $10 \mathrm{rpm}$ because foam formation was observed at higher rotation speed. With the selected rotation speed, blood was well mixed as the wings formed by the tightly fixed PDMS dipped in the blood with every rotation of the vial.

All PDMS to tissue ratios used in the passive sampling experiments were calculated based on the negligible depletion criterion [51]. Since blood was expected to have a lower concentration of target chemicals compared to solid tissues such as liver [35], a high PDMS to blood ratio was used to ensure a nearly exhaustive extraction (mass transfer of $60-80 \%$ ) according to Jin et al. [23]. 


\section{PDMS extraction}

After equilibrium was attained after 7 days, the PDMS was removed from the tissue. Adhering tissue or blood on the PDMS surface was wiped off with lint-free paper wipes. The PDMS was dipped into water, dried with lint-free paper wipes, and weighed. The mass gain caused by co-extracted matrix components of the different tissues was recorded. Extraction of PDMS was performed twice with approx. $1 \mathrm{~mL}$ EA per $0.1 \mathrm{~g}$ PDMS for $2 \mathrm{~h}$ on a roller mixer. The combined extracts were transferred to a $1.5 \mathrm{~mL}$ vial, blown down under a gentle stream of nitrogen, and dissolved in $50 \mu \mathrm{L}$ EA or spiked with $50 \mu \mathrm{L}$ of an appropriate analyte solution either for calibration or validation (see below). The samples were stored in the freezer at $-20{ }^{\circ} \mathrm{C}$ until analysis.

\section{Preparation of standard and spiking solutions}

Calibration mixtures of all analytes (ESM, Table S1) were prepared in concentrations of $1,5,10,30,80,250$ and $750 \mathrm{pg} \mu \mathrm{L}^{-1}$ in EA. Matrix extracts after PDMS sampling with isotopically labeled internal standard solution were used as blanks. The internal standard solution for calibration and also quantitation of human samples consisted of ${ }^{13} C_{12}$ - PCB congeners $28,52,101,118,138,153$ and $180,{ }^{13} C_{3}$-atrazine, chlorpyrifos-methyl- $d_{6}$, chlorpyrifos-ethyl- $d_{10}$, diazinon- $d_{10}$, tris-chloroethyl phosphate- $d_{12}$, triphenyl phosphate- $d_{15}$, DDT- $d_{8}$, tributyl phosphate- $d_{27}$ and metolachlor- $d_{6}$. The concentration in the final mixture (50 $\mu \mathrm{LEA})$ was $50 \mathrm{pg} \mathrm{\mu L}^{-1}$ for each of the labeled PCB congeners and between 100 and $400 \mathrm{pg} \mu \mathrm{L}^{-1}$ for the other labeled compounds depending on the response with sample matrix. Two different spike mixtures for assessing the intraday and interday precision of the method were prepared to yield low ( $20 \mathrm{pg} \mu \mathrm{L}^{-1}$, Q low $)$ and high (500 pg $\mu \mathrm{L}^{-1}, Q_{\text {high }}$ ) concentrations of all analytes in the final matrix extracts.

\section{Instrumental analysis and direct sample introduction}

GC-MS/MS analysis was carried out using an Agilent 7890 GC system with 7010 Triple Quadrupole MS (Agilent Technologies, USA) with a High Efficiency Source (HES) applying an EI energy of $70 \mathrm{eV}$. A Thermal Desorption Unit (TDU 2) combined with a Cold Injection System (CIS 4) PTV injector (GERSTEL GmbH, Mülheim a. d. Ruhr, Germany) was used for injection. A volume of $1 \mu \mathrm{L}$ sample extract was injected into the TDU tubes including $\mu$-vials. Maintenance of consumables involved in the DSI process is described in the ESM, Section S3. TDU was operated in splitless mode allowing an efficient transfer to the CIS. The initial temperature of the TDU program was $30{ }^{\circ} \mathrm{C}$ and raised to $300{ }^{\circ} \mathrm{C}$ at $720{ }^{\circ} \mathrm{C} \min ^{-1}$ ( $3 \mathrm{~min}$ ). The helium flow was kept at $50 \mathrm{~mL} \mathrm{~min}{ }^{-1}$ until thermodesorption cycle was completed.
The transfer line of the TDU was set to $300{ }^{\circ} \mathrm{C}$. The CIS was operated in solvent vent mode with an empty baffled liner. During thermal desorption, the CIS temperature was set to $-30{ }^{\circ} \mathrm{C}$ for cryofocusing. After finishing the thermal desorption cycle, the temperature of the injector was raised to $300{ }^{\circ} \mathrm{C}$ at $12{ }^{\circ} \mathrm{C} \mathrm{s}^{-1}$ (3 min) ensuring a complete transfer of the analytes to the column.

Chromatographic separation of the analytes was achieved on a HP5-MS UI® capillary column (30 m length, $0.25 \mu \mathrm{m}$ i.d., $0.25 \mu \mathrm{m}$ film thickness, J\&W Scientific, USA). The oven was programmed as follows: $60{ }^{\circ} \mathrm{C}(3 \mathrm{~min})$ to $210{ }^{\circ} \mathrm{C}$ at $30{ }^{\circ} \mathrm{C} \mathrm{min}{ }^{-1}$ (5 min), to $240{ }^{\circ} \mathrm{C}$ at $3{ }^{\circ} \mathrm{C} \mathrm{min}^{-1}$ and finally to $300^{\circ} \mathrm{C}$ at $40{ }^{\circ} \mathrm{C} \mathrm{min}^{-1}$ (5 min). The run time of the $\mathrm{GC}$ oven program was $26 \mathrm{~min}$. Total run time for processing one sample including the exchange of thermal desorption liner, thermal desorption process, and chromatographic separation was $37 \mathrm{~min}$. Helium (6.0 purity) was used as carrier gas in constant flow mode at $1.3 \mathrm{~mL} \mathrm{~min}^{-1}$ and the solvent delay was set at $6.3 \mathrm{~min}$. The MS transfer line was kept at $250{ }^{\circ} \mathrm{C}$, the ion source at $230{ }^{\circ} \mathrm{C}$, and both quadrupoles were operated at $150{ }^{\circ} \mathrm{C}$. Nitrogen was used as collision gas at a flow of

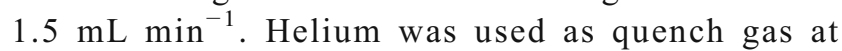
$2.25 \mathrm{ml} \mathrm{min}^{-1}$. Selective and sensitive mass transitions under specific collision energies (CEs) were determined for each analyte (ESM, Table S2).

After every injection, the syringe was rinsed eight times each with $\mathrm{CH}$ followed by EA preventing clogging and sample carryover which may have been caused by remaining matrix components in the syringe plunger. MassHunter Workstation Software-Data Acquisition (Version B.07.04, Agilent Technologies, USA) with an integrated Maestro software (Version 1.4.36.16, GERSTEL GmbH, Mülheim a. d. Ruhr, Germany) was used for data acquisition and instrument control. Data analysis was carried out with MassHunter Workstation Software QQQ Quantitative Analysis (Version B.07.01 SP1, Agilent Technologies, USA).

\section{Method validation}

The validation procedure included the assessment of linearity, matrix effects, limits of detection and quantitation as well as intraday and interday precision [52]. Calibration curves were derived from plotting the relative response (RR) against the concentrations of the calibration standards. The relative response was calculated by dividing the response of the analyte by the response of the corresponding isotopically labeled standard. Least square linear regression was carried out using the software GraphPad Prism (Version 8.3, San Diego, CA). Matrix effects (ME) were investigated by comparing the slopes of the calibration curves prepared in pure solvent and prepared in extracts of the different matrices (matrix-matched calibrations) according to Eq. (1) [52]. 
$\operatorname{ME}[\%]=\left(\frac{\text { slope } \text { matrix }- \text { matched standards }}{\text { slope standards in solvent }}\right) * 100 \%$

Limits of detection (LOD) and limits of quantitation (LOQ) were determined from liver blank samples. LOD was calculated by 3.3 times the standard deviation of the relative response of the blank divided by the slope of the calibration curve, whereas LOQ was calculated by 10 times the standard deviation of the relative response of the blank divided by the slope of the calibration curve [53]. The standard deviation of the relative responses of the blank was derived by injection of neat matrix extracts fortified with a solution containing the isotopically labeled internal standard mixture.

Intraday $(n=10)$ and interday $(n=3)$ precisions were de-

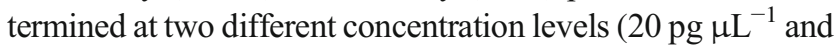
$500 \mathrm{pg} \mathrm{L}^{-1}$ ) and expressed as relative standard deviation $(\mathrm{RSD} \%)$. In case of testing the intraday precision, 10 replicates of the two concentration levels were injected consecutively on the same day. Three injections on four different days represented the interday precision. Potential carryover of chemicals was checked by injecting two EA blanks without matrix after every series.

\section{Results and discussion}

\section{Determination of the total lipid content in liver, brain, adipose tissue and blood}

Total lipids were determined gravimetrically after solvent extraction. Solvent and negative control blanks gave a low background with $0.05 \%$ of weight extracted, which were both used for blank subtraction. Positive controls showed good recoveries with a mean extraction efficacy of $99.8 \%$ for triolein and $99.1 \%$ for POPC. The tissues varied in lipid content from 0.3 to $91 \%\left(\mathrm{~m}_{\text {lipid }} \mathrm{m}_{\text {tissue }}{ }^{-1}\right)$ and triplicate analysis of blank subtracted and recovery corrected samples showed a low standard deviation (Table 1).

\section{Co-extracted matrix components in PDMS}

During passive sampling, not only the target analytes but also undesired lipophilic matrix was taken up by the PDMS. This led to a weight gain of the PDMS, which was monitored by weighing the PDMS before and after passive sampling. The co-extracted matrix can be attributed to lipids or lipid-like substances [23]. Different amounts of co-extractives were extracted depending on the tissue sampled. For blood, there was only $0.05 \%$ of weight gain $\left(\mathrm{m}_{\text {coextractives }} \mathrm{m}_{\mathrm{PDMS}}{ }^{-1}\right)$, but in fat tissue, $0.8 \%$ lipid was co-extracted (Table 1). Accordingly, different amounts of co-extractives were injected into the GC (Table 1).

\section{Problems with interfering matrix components in conventional GC-MSD methods}

The analytical method was first tested on a single quadrupole mass spectrometer (GC-MSD) system with SSL injector (details can be found in the ESM, Section S4) where different problems caused by the co-extracted matrix occurred during method development. Figure 1 a shows a full scan chromatogram $(m / z, 50-550)$ of neat pork liver blank matrix extract which was measured on the GC-MSD. The co-extracted matrix components were identified using the NIST® Database. Volatile as well as non-volatile matrix components produced a high background, since the whole matrix that was present in the extract was injected. The PDMS gained $0.63 \%$ of weight

Table 1 Total lipid content (with standard deviation SD) and co-extracted matrix components after passive sampling with PDMS of the respective tissue

\begin{tabular}{|c|c|c|c|c|}
\hline Tissue & $\begin{array}{l}\text { Total lipid content } \\
\mathrm{m}_{\text {lipid }} \mathrm{m}_{\text {tissue }}^{-1}(\mathrm{SD})\left[\mathrm{g}_{\text {lipid }} \mathrm{kg}-\right. \\
\text { tissue }\end{array}$ & $\begin{array}{l}\text { Co-extractives in PDMS } \\
\mathrm{m}_{\text {coextractives }} \mathrm{m}_{\text {PDMS }}{ }^{-1}\left[\mathrm{mg}_{\text {coextractives }} /\right. \\
\left.\mathrm{g}_{\text {PDMS }}\right]\end{array}$ & $\begin{array}{l}\text { PDMS used for e } \\
\text { xtraction m } \\
{\left[\mathrm{mgDMS}_{\text {PDMS }}\right]}\end{array}$ & $\begin{array}{l}\text { Amount of co-extractives injected } \\
\text { in GC with } 1 \mu \mathrm{L} \text { injection volume } \\
\text { of final extract with } 50 \mu \mathrm{L} \text { vol- } \\
\text { ume }[\mu \mathrm{g}]\end{array}$ \\
\hline Pork liver tissue & $39.7(0.8)$ & 6.31 & 125 & 15.8 \\
\hline Pork brain tissue & $105.0(0.6)$ & 1.37 & 330 & 9.0 \\
\hline Pork fat tissue & $809.6(5.1)$ & 7.71 & 125 & 19.3 \\
\hline Pork blood & $3.1(0.1)$ & 0.45 & 400 & 3.7 \\
\hline Human liver tissue & $36.2(0.7)$ & 6.80 & 125 & 17.0 \\
\hline $\begin{array}{l}\text { Human brain } \\
\text { tissue }\end{array}$ & $88.4(0.6)$ & 1.12 & 330 & 7.4 \\
\hline $\begin{array}{l}\text { Human adipose } \\
\text { tissue }\end{array}$ & $910.2(5.6)$ & 7.60 & 125 & 19.0 \\
\hline Human blood & $5.3(0.2)$ & 0.50 & 400 & 4.3 \\
\hline
\end{tabular}


Fig. 1 Panel a shows a full scan chromatogram $(\mathrm{m} / \mathrm{z}, 50-550)$ of pork liver blank matrix extract measured with GC-MSD. A full scan chromatogram $(\mathrm{m} / \mathrm{z}, 50-550)$ of pork liver blank matrix extract measured with DSI GC-MS/MS is displayed in panel $\mathbf{b}$. The injection volume was $1 \mu \mathrm{L}$ of PDMS extract with a total amount of $16 \mu \mathrm{g}$ co-extractives coinjected in both measurements. Identified co-extractives in both chromatograms were hexadecanoic acid (HA), cholesterol (CL), oleic acid (OA), linoleic acid (LA) overlapping with octadecenoic acid (ODA), and glyceryl oleate (GO)
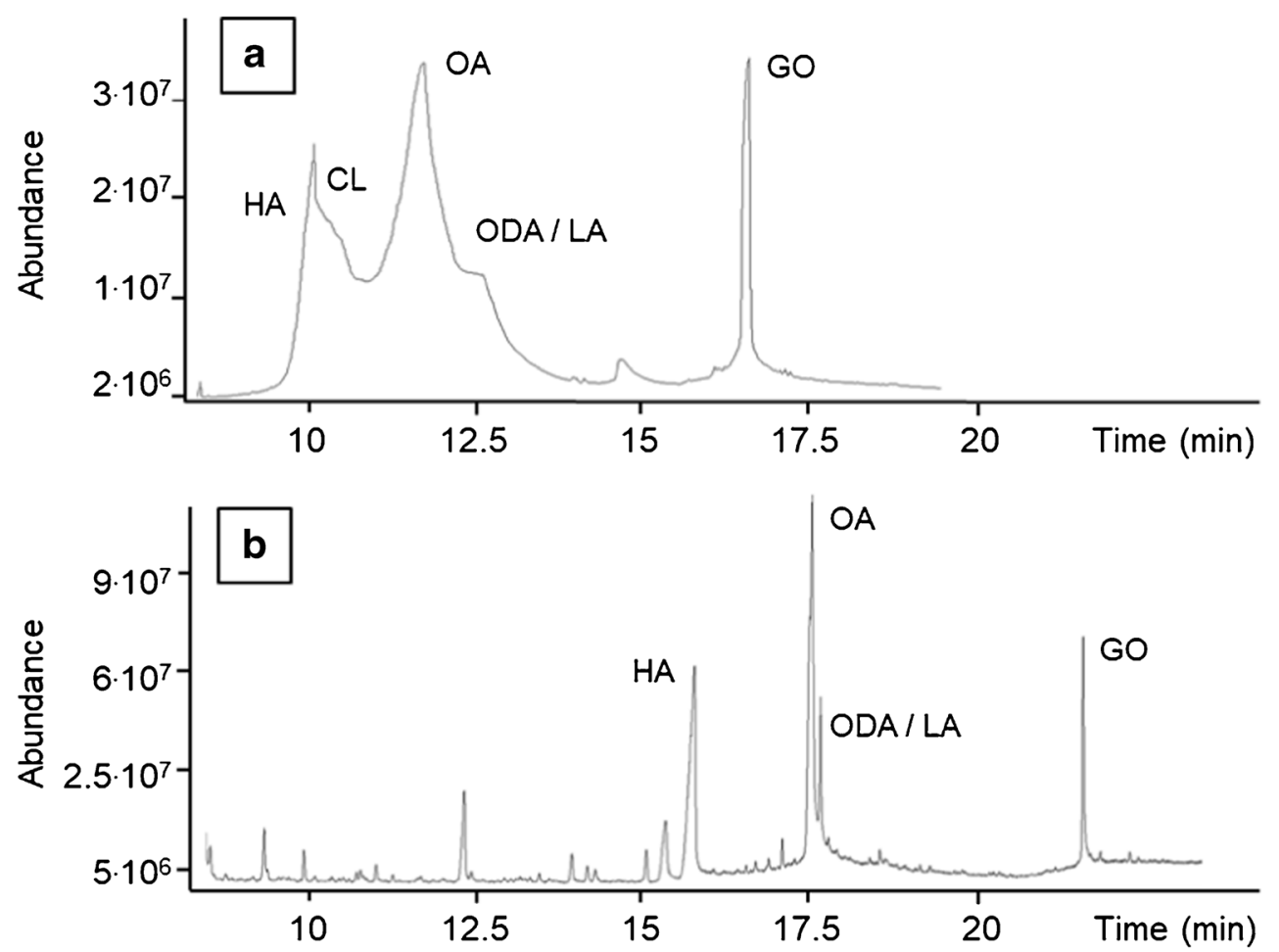

during equilibrium passive sampling with liver (corresponding to $16 \mu \mathrm{g}$ co-extractives) and most of this weight gain could be attributed to lipids. Peaks in Fig. 1 were identified as hexadecanoic acid (HA) and cholesterol (CL), oleic acid (OA), linoleic acid (LA) overlapping with octadecenoic acid (ODA), and glyceryl oleate (GO). The peak at $15 \mathrm{~min}$ in Fig. 1 a could potentially be octadecanal (OL), but this identification is inconsistent with the Kovats retention index. OL would be expected to elute before OA. We therefore did not label this peak. The early eluting CL peak can possibly be caused by a carryover, since according to the retention indices, CL should elute at the rear of the chromatogram.

By measuring a $50 \mathrm{pg} \mu \mathrm{L}^{-1}$ solution spiked on blank liver matrix in selected ion monitoring (SIM) mode, all compounds could be detected, but a raising baseline at $11 \mathrm{~min}$ due to coeluting matrix components and ghost peaks were observed (ESM Fig. S1) that adversely affected quantitation of coeluting analytes and the long-term stability of the measurements. For these reasons, this method is unsuitable for the analysis of the PDMS extracts unless clean-up is performed prior to $\mathrm{GC}$ analysis.

\section{Reduction of matrix effects by the use of DSI GC- MS/MS}

To reduce the matrix effects, a GC-MS/MS system with a special injector was selected. The injection system consisted of the TDU which was connected to the CIS.
The liquid sample extract was injected into the TDU at temperatures below the boiling point of the solvent. Disposable $\mu$-vials were used, which were placed inside a TDU tube with notch. The amount of interfering matrix that was transferred onto the analytical column was reduced by this method but some volatile matrix components still entered the system. An improvement of the method with TDU (Fig. 1b) compared with the classical liquid injection method (Fig. 1a) was the partial removal of interfering non-volatile matrix components at the injection system. Only volatile matrix components including free fatty acids could be identified in the DSI samples (Fig. 1b).

During the thermodesorption cycle, non-volatile matrix components remained in the $\mu$-vial (ESM, Fig. S6-visible lipid droplets). Volatile or semi-volatile matrix components, for example, fatty acids, were refocused in the CIS at lower temperatures before the start of the GC run together with the target analytes present in the sample extract. The TDU was operated in splitless mode, but a small amount of volatile matrix components was removed by the split vent through a forced split flow of $3 \mathrm{~mL} \mathrm{~min}^{-1}$. Before every sample injection, the TDU tube was exchanged. Compared with the option of combining TDU tubes with $\mu$-vials, the use of glass wool in TDU tubes was less efficient and introduced the risk that glass wool entered the GC system. This led to generation of additional active sites in the injector port and carryover of analytes. Parameters for DSI method optimization are outlined in the ESM, Section S3. 


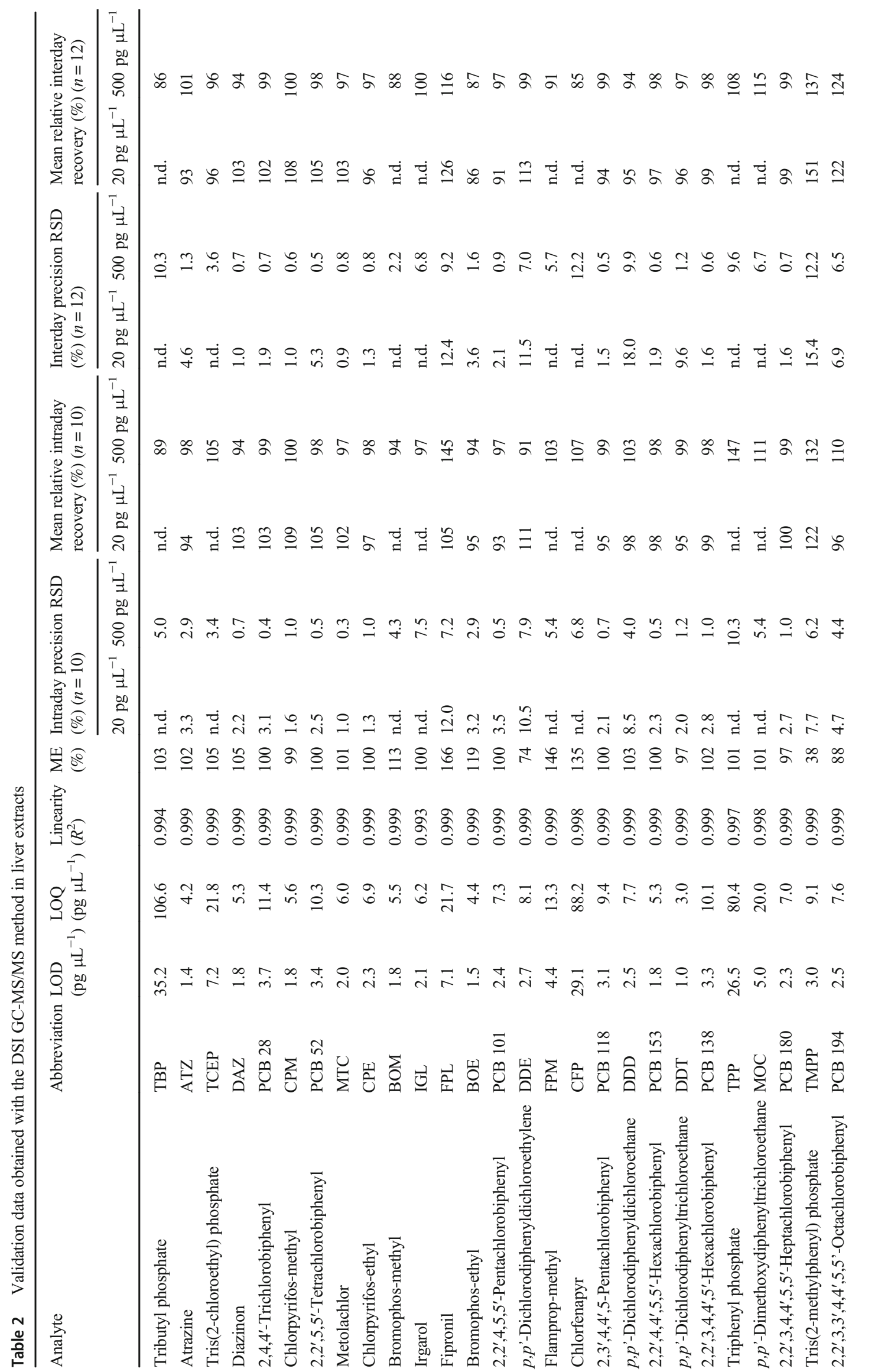




\section{Method validation}

Analysis for the 27 chemicals was performed in MRM mode (ESM, Fig. S2). Calibration curves of all analytes were linear $\left(R^{2}>0.994\right)$ over the measured concentration range (Table 2) and slopes with standard errors calculated by error propagation are reported in ESM (Table S4). Blanks of pure solvent, cleaned PDMS (without matrix), and liver matrix extracts showed no contamination and the results were below LOQ (ESM, Fig. S3-S5). Matrix effects (ME) for the three different tissues and blood are visualized in Fig. S7. For the assessment of matrix effects, the slopes of the different matrix-matched calibrations were compared with the slope of a calibration in EA according to Eq. (1) using the slopes listed in ESM Table S4. We considered an ME of $100 \% \pm 20 \%$ as acceptable range (dotted lines in Fig. S7). For 19 compounds (all PCBs, all organophosphorus pesticides, ATZ, TCEP, MTC, TPP, and DDT), ME values ranging between 88 and $120 \%$ and the standard error for all four matrices were obtained (ESM, Table S5). For Irgarol (IGL), DDD, and DDE, ME values in blood matrix were up to $125 \%$ and between 74 and $122 \%$ for liver, brain, and adipose tissue. Only four chemicals, flamprop-methyl (FPM), fipronil (FPL), chlorfenapyr (CFP), and tris(2-methylphenyl) phosphate (TMPP), showed high ME values, up to $166 \%$. For TMPP, signal suppression down to $38 \%$ was observed in liver matrix, indicating that matrixmatched calibration for quantification of these analytes must be employed ensuring an accurate quantification.

For method validation, liver was chosen as most complex matrix due to the low lipid content (4\%) but large quantity of co-extracted material (Table 1). LOQs ranged from 3 to $11 \mathrm{pg} \mu \mathrm{L}^{-1}$ for most pesticides and PCBs (Table 2). Organophosphorus flame retardants (OFRs) showed higher

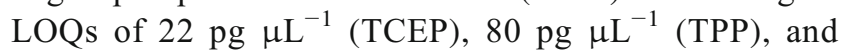
$107 \mathrm{pg} \mu \mathrm{L}^{-1}$ (tributyl phosphate, TBP) compared with POPs like PCB $52\left(\mathrm{LOQ}=10 \mathrm{pg} \mu \mathrm{L}^{-1}\right)$ and organophosphorus pesticides like CPM $\left(\mathrm{LOQ}=5.7 \mathrm{pg} \mathrm{L}^{-1}\right)$. Higher LOQ values for pesticides like dimethoxydiphenyltrichloroethane (MOC) and

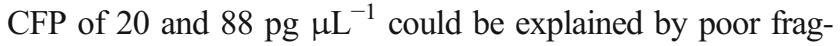
mentation during MS/MS analysis of these compounds in addition to co-extracted matrix present in the extracts. LOD and LOQ values expressed on a lipid weight basis for comparison with other methods can be found in the ESM, Table S6.

Intraday precision was carried out by injecting 10 simultaneously prepared liver sample extracts containing $20 \mathrm{pg}_{\mu \mathrm{L}} \mathrm{L}^{-1}$

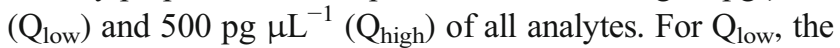
results ranged between an RSD of $1 \%$ for MTC and $12 \%$ for FPL (Table 2). For $\mathrm{Q}_{\text {high }}$, the best result was obtained for PCB 28 with an RSD of $0.3 \%$, whereas the highest RSD was calculated for TPP of $10 \%$ (Table 2). Relative recoveries for intraday precision ranged from 93 to $111 \%$ for $\mathrm{Q}_{\text {low }}$ and from 89 to $110 \%$ for $\mathrm{Q}_{\text {high }}$, respectively. Interday precisions were measured by injecting three samples on four different days with a relative recovery of 86 to $126 \%$ for $\mathrm{Q}_{\text {low }}$ and 85 to $137 \%$ for $Q_{\text {high }}$, respectively. RSD values were 1 to $18 \%$ for $\mathrm{Q}_{\text {low }}$ and 1 to $12 \%$ for $\mathrm{Q}_{\text {high }}$. Relative recovery was relatively high for TMPP (151\% for $\mathrm{Q}_{\text {low }}$ and $137 \%$ for $\mathrm{Q}_{\text {high }}$ ). Q Q low could not be quantified for the OFRs as well as for the pesticides MOC, CFP and FPL due to the high LOQs of these compounds (Table 2).

The developed method reduced matrix effects and minimized the effort for GC maintenance and sped up sample throughput because the sample extracts could be submitted to GC analysis without any additional clean-up. Nonetheless, the analysis of OFRs remains challenging. The LODs and LOQs were higher compared with other chemicals in this study and also higher deviations in relative recoveries of the spiked samples were observed. One reason for this observation could be that the OFRs tend to sorb to active sites generated by the additional glass surfaces of the TDU tubes and the $\mu$-vials.

\section{Application to human samples}

The validated method was applied to determine the concentrations of the 27 analytes in human tissues. PDMS and solvent blanks showed no contamination. DDT and its metabolites DDD and DDE as well as the highly chlorinated PCB congeners 138, 153 and 180 were detected in the PDMS extracts of human tissues. In blood, only DDE could be detected with a concentration below the LOQ (Table 3).

Other non-persistent or more hydrophilic pesticides and chemicals included in the method were not detected. The measured PDMS concentrations were converted to tissue concentrations (liver, brain, and adipose tissue) normalized to the lipid content of the respective tissue (Table 4) using partition coefficients between lipid and PDMS ( $\left.K_{\text {lipid/PDMS }}\right)$ and tissue and PDMS ( $\left.K_{\text {tissue/PDMS }}\right)$ predicted with the UFZ-LSER database [54], as described in the ESM, Section S6. A comparison of the results normalized to the lipid content based on experientially determined $K_{\text {lipid/PDMS }}$ from Jahnke et al. (2008) [25] is shown in the ESM, Table S9 and Fig. S8. No concentrations were calculated for the blood sample since all PDMS concentrations were below LOQ.

Previous studies investigated the burden of chlorinated POPs in several human tissues including liver $[6,7,55]$, brain $[7,55]$, and adipose tissue $[5,6,56]$. The collected tissues were Soxhlet-extracted followed by clean-up employing GPC or sulfuric acid with acid silica gel column. Quantification was conducted either with GC-ECD (electron capture detector) or GC-MSD. Compared with our study, the results showed a similar pattern of the detected analytes with DDE as highly abundant pesticide metabolite, DDD only detected in liver as metabolic active organ, and PCB congeners 138, 153 and 180 present in all tissues as most abundant PCB congeners (comparison with results from Chu et al. [55], 
Table 3 Application of the method for the analysis of human tissues. Reported concentrations (C) in $n g \mathrm{~g}_{\mathrm{PDMS}}{ }^{-1}$ are given as mean with corresponding standard deviation (SD) from triplicate extractions

\begin{tabular}{|c|c|c|c|c|}
\hline Compound & $\begin{array}{l}\text { Blood } C_{\text {blood }} \text { (ng } \\
\text { g PDMS }^{-1} \text { ) }\end{array}$ & $\begin{array}{l}\text { Liver tissue } \mathrm{C}_{\text {liver }} \\
\left(\mathrm{ng} \mathrm{g}_{\mathrm{PDMS}}{ }^{-1}\right)\end{array}$ & $\begin{array}{l}\text { Brain tissue } \mathrm{C}_{\text {brain }} \\
\left(\mathrm{ng} \mathrm{g}_{\mathrm{PDMS}}{ }^{-1}\right)\end{array}$ & $\begin{array}{l}\text { Adipose tissue } C_{\text {adipose tissue }} \\
\left(\text { ng g }_{\text {PDMS }}{ }^{-1} \text { ) }\right.\end{array}$ \\
\hline PCB 138 & $<$ LOD & $1.5(0.2)$ & $1.5(0.2)$ & $5.2(0.5)$ \\
\hline PCB 153 & $<\mathrm{LOD}$ & $1.9(0.1)$ & $2.5(0.2)$ & $8.7(0.2)$ \\
\hline PCB 180 & $<$ LOD & $1.2(0.2)$ & $0.8(0.3)$ & $5.8(0.7)$ \\
\hline DDE & $<\mathrm{LOQ}$ & $90.0(0.8)$ & $58.0(7.6)$ & $115.9(21.2)$ \\
\hline DDD & $<$ LOD & $2.4(0.3)$ & $<$ LOD & $<$ LOD \\
\hline DDT & $<\mathrm{LOD}$ & $2.0(0.1)$ & $1.2(0.1)$ & $2.1(0.1)$ \\
\hline
\end{tabular}

ESM, Fig. S9). For instance, Chu et al. [55] detected also lower chlorinated PCBs like PCB 52, PCB 101 and PCB 118 (ESM Table S10). Due to the negligible depletion criterion in passive sampling methods, only up to $5 \%$ of the analytes present in the tissue were extracted leading to concentrations below LOQ of these chemicals. In contrast to the non-depletive method, Soxhlet extraction represent a near exhaustive extraction method of the tissue enabling the analysis of environmental contaminants at much more lower trace levels than the detected concentrations of DDE, PCB 153 and PCB 180 in this study. Considering even lower concentration levels of target analytes in liver, brain and blood compared to adipose tissue, the usage of higher PDMS to sample ratio increasing the sampled amount of analytes or the application of large volume injection could compensate for this limitation.

\section{Conclusions}

The analysis of tissue extracts obtained from equilibrium passive sampling was possible without further extract clean-up employing DSI GC-MS/MS. The advantage of the injection of the liquid extract via TDU was that nonvolatile matrix components were removed offering the possibility of straight direct analysis of the sample extracts reducing time for sample preparation and costs in terms of material like solvents or longer column lifetime. The method was successfully applied to human tissues with varying lipid content. Hence, the method should be transferable to other tissues such as kidney, muscle and lung. The method was found to be suitable for POPs and non-persistent pesticides. Further optimization needs to be conducted for organophosphorus flame retardants. Analyte protectants could be used to cover active sites, which might lead to more robust results [40, 57, 58].

If passive sampling with PDMS is employed, only a small fraction of the analyte (below 5\% to meet the negligible depletion criterion) is extracted, and thus, analytical detection limits might not be met. This could be the reason why lower chlorinated PCB congeners which might be present in the human tissues could not be detected in this study. But it is possible to work with depletive conditions (usage of a higher PDMS volumes in relation to the sample amount) in future studies as has been shown for blood in the present study and for sediments in the literature [59]. In these cases, the time to reach equilibrium might be longer. Another option would be to use large volume injection for the analysis of chemicals present only at trace levels to lower the detection limits in accordance with the more co-injected matrix. Furthermore, to enable a more precise determination of tissue concentrations, experimentally determined $K_{\text {tissue/ }}$ PDMS are required for the chemicals investigated.
Table 4 Summary of concentrations $(\mathrm{C})$ reported in $\mathrm{ng}$ $\mathrm{g}_{\mathrm{lw}}{ }^{-1}(\mathrm{lw}=$ lipid weight $)$ and $\mathrm{ng}$ $\mathrm{g}_{\mathrm{ww}}{ }^{-1}(\mathrm{ww}=$ wet weight $)$

\begin{tabular}{|c|c|c|c|c|c|c|}
\hline \multirow[t]{2}{*}{ Compound } & \multicolumn{2}{|c|}{ Liver tissue } & \multicolumn{2}{|c|}{ Brain tissue } & \multicolumn{2}{|l|}{ Adipose tissue } \\
\hline & $\begin{array}{l}\mathrm{C}_{\text {liver }}(\mathrm{ng} \\
\left.\mathrm{g}_{\mathrm{lw}}^{-1}\right)\end{array}$ & $\begin{array}{l}\mathrm{C}_{\text {liver }} \text { (ng } \\
\left.\mathrm{g}_{\mathrm{ww}}-1\right)\end{array}$ & $\begin{array}{l}\mathrm{C}_{\text {brain }}(\mathrm{ng} \\
\left.\mathrm{g}_{1 \mathrm{w}}{ }^{-1}\right)\end{array}$ & $\begin{array}{l}\mathrm{C}_{\text {brain }} \text { (ng } \\
\left.\mathrm{g}_{\mathrm{ww}}{ }^{-1}\right)\end{array}$ & $\begin{array}{l}\mathrm{C}_{\text {adipose tissue }} \text { (ng } \\
\mathrm{g}_{\mathrm{lw}}{ }^{-1} \text { ) }\end{array}$ & $\begin{array}{l}\mathrm{C}_{\text {adipose tissue }}(\mathrm{ng} \\
\mathrm{g}_{\mathrm{ww}}{ }^{-1} \text { ) }\end{array}$ \\
\hline PCB 138 & 25.6 & 1.0 & 25.6 & 2.1 & 88.6 & 75.0 \\
\hline PCB 153 & 29.5 & 1.1 & 38.9 & 3.3 & 135.2 & 114.5 \\
\hline PCB 180 & 25.2 & 0.9 & 16.8 & 1.4 & 121.6 & 102.9 \\
\hline DDE & 1761.0 & 64.5 & 1134.9 & 94.7 & 2267.8 & 1919.6 \\
\hline DDD & 40.9 & 1.6 & - & - & - & - \\
\hline DDT & 32.5 & 1.3 & 19.5 & 1.6 & 34.2 & 28.9 \\
\hline
\end{tabular}


Acknowledgments Sandra Jäsch is acknowledged for her help and advices improving the DSI method. We thank Andrea Pfennigsdorff, Darya Gedankina, Sophia Mälzer, and Niklas Wojtysiak for supporting the GC measurements and the logistic support during experiments. Ingo Bechmann, Hannah Frenzel, and Sabine Löffler are acknowledged for collecting the human tissue samples. Luise Henneberger and Rita Schlichting are thanked for reviewing earlier versions of the manuscript.

Funding Information Open Access funding provided by Projekt DEAL.

\section{Compliance with ethical standards}

All experiments with mammalian tissues were conducted according to the principles of the Declaration of Helsinki. Human post-mortem tissues were obtained from a body donator. While alive, the body donor gave an informed and written consent to the body donation for teaching and research purposes. Institutional approval for the use of the post-mortem tissues of human body donors was obtained from the Institute of Anatomy, University of Leipzig. The body donor program is regulated by the Saxonian Death and Funeral Act of 1994 (third section, paragraph 18 item 8).

Conflict of interest The authors declare that they have no conflict of interest.

Open Access This article is licensed under a Creative Commons Attribution 4.0 International License, which permits use, sharing, adaptation, distribution and reproduction in any medium or format, as long as you give appropriate credit to the original author(s) and the source, provide a link to the Creative Commons licence, and indicate if changes were made. The images or other third party material in this article are included in the article's Creative Commons licence, unless indicated otherwise in a credit line to the material. If material is not included in the article's Creative Commons licence and your intended use is not permitted by statutory regulation or exceeds the permitted use, you will need to obtain permission directly from the copyright holder. To view a copy of this licence, visit http://creativecommons.org/licenses/by/4.0/.

\section{References}

1. Weber R, Gaus C, Tysklind M, Johnston P, Forter M, Hollert H, et al. Dioxin- and POP-contaminated sites-contemporary and future relevance and challenges. Environ Sci Pollut R. 2008;15(5):363-93.

2. Voorspoels S, Covaci A, Maervoet J, De Meester I, Schepens P. Levels and profiles of PCBs and OCPs in marine benthic species from the Belgian North Sea and the Western Scheldt Estuary. Mar Pollut Bull. 2004;49(5-6):393-404.

3. Roscales JL, Vicente A, Ramos L, Jiménez B. Miniaturised sample preparation method for the multiresidual determination of regulated organohalogenated pollutants and related compounds in wild bird eggs. Anal Bioanal Chem. 2017;409(20):4905-13.

4. Letcher RJ, Norstrom RJ, Muir DCG. Biotransformation versus bioaccumulation: sources of methyl sulfone PCB and 4,4 '-DDE metabolites in the polar bear food chain. Environ Sci Technol. 1998;32(11):1656-61.

5. Covaci A, de Boer J, Ryan JJ, Voorspoels S, Schepens P. Distribution of organobrominated and organochlorinated contaminants in Belgian human adipose tissue. Environ Res. 2002;88(3):210-8.

6. Covaci A, Voorspoels S, Roosens L, Jacobs W, Blust R, Neels H. Polybrominated diphenyl ethers (PBDEs) and polychlorinated biphenyls (PCBs) in human liver and adipose tissue samples from Belgium. Chemosphere. 2008;73(2):170-5.
7. Chu SG, Covaci A, Schepens P. Levels and chiral signatures of persistent organochlorine pollutants in human tissues from Belgium. Environ Res. 2003;93(2):167-76.

8. Fromme H, Hilger B, Albrecht M, Gries W, Leng G, Volkel W. Occurrence of chlorinated and brominated dioxins/furans, PCBs, and brominated flame retardants in blood of German adults. Int $\mathrm{J}$ Hyg Environ Health. 2016;219(4-5):380-8.

9. Pellizzari ED, Woodruff TJ, Boyles RR, Kannan K, Beamer PI, Buckley JP, Wang AL, Zhu YY, Bennett DH, Out EICH. Identifying and prioritizing chemicals with uncertain burden of exposure: opportunities for biomonitoring and health-related research. Environmental Health Perspectives. 2019;127(12).

10. van de Merwe JP, Hodge M, Whittier JM, Lee SY. Analysing persistent organic pollutants in eggs, blood and tissue of the green sea turtle (Chelonia mydas) using gas chromatography with tandem mass spectrometry (GC-MS/MS). Anal Bioanal Chem. 2009;393(6):1719-31.

11. Hildmann F, Gottert C, Frenzel T, Kempe G, Speer K. Pesticide residues in chicken eggs - a sample preparation methodology for analysis by gas and liquid chromatography/tandem mass spectrometry. J Chromatogr A. 2015;1403:1-20.

12. Castillo M, Gonzalez C, Miralles A. An evaluation method for determination of non-polar pesticide residues in animal fat samples by using dispersive solid-phase extraction clean-up and GC-MS. Anal Bioanal Chem. 2011;400(5):1315-28.

13. Jahnke A, Mayer P, Broman D, McLachlan MS. Possibilities and limitations of equilibrium sampling using polydimethylsiloxane in fish tissue. Chemosphere. 2009;77(6):764-70.

14. Jahnke A, Mayer P, Schafer S, Witt G, Haase N, Escher BI. Strategies for transferring mixtures of organic contaminants from aquatic environments into bioassays. Environ Sci Technol. 2016;50(11):5424-31.

15. Jahnke A, Witt G, Schafer S, Haase N, Escher BI. Combining passive sampling with toxicological characterization of complex mixtures of pollutants from the aquatic environment. In: Reifferscheid $\mathrm{G}$, Buchinger $\mathrm{S}$, editors. In vitro environmental toxicology - concepts, application and assessment. Advances in Biochemical Engineering-Biotechnology. 157. Cham: Springer International Publishing Ag; 2017. pp. 225-61.

16. Jahnke A, Mayer P, Adolfsson-Erici M, McLachlan MS. Equilibrium sampling of environmental pollutants in fish: comparison with lipidnormalized concentrations and homogenization effects on chemical activity. Environ Toxicol Chem. 2011;30(7):1515-21.

17. Allan IJ, Baek K, Haugen TO, Hawley KL, Hogfeldt AS, Lillicrap AD. In vivo passive sampling of nonpolar contaminants in brown trout (Salmo trutta). Environ Sci Technol. 2013;47(20):11660-7.

18. Jahnke A, Mayer P, McLachlan MS, Wickstrom H, Gilbert D, MacLeod M. Silicone passive equilibrium samplers as 'chemometers' in eels and sediments of a Swedish lake. Environ Sci-Proc Imp. 2014;16(3):464-72.

19. Jin L, Gaus C, van Mourik L, Escher BI. Applicability of passive sampling to bioanalytical screening of bioaccumulative chemicals in marine wildlife. Environ Sci Technol. 2013;47(14):7982-8.

20. Ossiander L, Reichenberg F, McLachlan MS, Mayer P. Immersed solid phase microextraction to measure chemical activity of lipophilic organic contaminants in fatty tissue samples. Chemosphere. 2008;71(8):1502-10.

21. Ulrich S, Kruggel S, Weigmann H, Hiemke C. Fishing for a drug: solid-phase microextraction for the assay of clozapine in human plasma. J Chromatogr B. 1999;731(2):231-40.

22. Tienpont B, David F, Desmet K, Sandra P. Stir bar sorptive extraction-thermal desorption-capillary GC-MS applied to biological fluids. Anal Bioanal Chem. 2002;373(1-2):46-55.

23. Jin L, Escher BI, Limpus CJ, Gaus C. Coupling passive sampling with in vitro bioassays and chemical analysis to understand 
combined effects of bioaccumulative chemicals in blood of marine turtles. Chemosphere. 2015;138:292-9.

24. Jin L, Gaus C, Escher BI. Adaptive stress response pathways induced by environmental mixtures of bioaccumulative chemicals in dugongs. Environ Sci Technol. 2015;49(11):6963-73.

25. Jahnke A, McLachlan MS, Mayer P. Equilibrium sampling: partitioning of organochlorine compounds from lipids into polydimethylsiloxane. Chemosphere. 2008;73(10):1575-81.

26. Erney DR, Pawlowski TM, Poole CF. Matrix-induced peak enhancement of pesticides in gas chromatography: is there a solution? Hrc-J High Res Chrom. 1997;20(7):375-8.

27. Hajslova J, Zrostlikova J. Matrix effects in (ultra) trace analysis of pesticide residues in food and biotic matrices. J Chromatogr A. 2003;1000(1-2):181-97.

28. Jahnke A, Mayer P. Do complex matrices modify the sorptive properties of polydimethylsiloxane (PDMS) for non-polar organic chemicals? J Chromatogr A. 2010;1217(29):4765-70.

29. Frenich AG, Bolanos PP, Vidal JLM. Multiresidue analysis of pesticides in animal liver by gas chromatography using triple quadrupole tandem mass spectrometry. J Chromatogr A. 2007;1153(1-2):194-202.

30. David F, Devos C, Dumont E, Yang Z, Sandra P, Huertas-Perez JF. Determination of pesticides in fatty matrices using gel permeation clean-up followed by GC-MS/MS and LC-MS/MS analysis: a comparison of low- and high-pressure gel permeation columns. Talanta. 2017;165:201-10.

31. Desforges JP, Eulaers I, Periard L, Sonne C, Dietz R, Letcher RJ. A rapid analytical method to quantify complex organohalogen contaminant mixtures in large samples of high lipid mammalian tissues. Chemosphere. 2017;176:243-8.

32. Steinbach P, Schwack W. Comparison of different solid-phaseextraction cartridges for a fatty acid cleanup of the ethyl acetate/ cyclohexane based multi-pesticide residue method EN 12393. J Chromatogr A. 2014;1323:28-38.

33. Lichtmannegger K, Fischer R, Steemann FX, Unterluggauer H, Masselter S. Alternative QuEChERS-based modular approach for pesticide residue analysis in food of animal origin. Anal Bioanal Chem. 2015;407(13):3727-42.

34. Plassmann MM, Schmidt M, Brack W, Krauss M. Detecting a wide range of environmental contaminants in human blood samplescombining QuEChERS with LC-MS and GC-MS methods. Anal Bioanal Chem. 2015;407(23):7047-54.

35. Usui K, Hashiyada M, Hayashizaki Y, Igari Y, Hosoya T, Sakai J, et al. Application of modified QuEChERS method to liver samples for forensic toxicological analysis. Forensic Toxicol. 2014;32(1):139-47.

36. Norli HR, Christiansen A, Deribe E. Application of QuEChERS method for extraction of selected persistent organic pollutants in fish tissue and analysis by gas chromatography mass spectrometry. J Chromatogr A. 2011;1218(41):7234-41.

37. Goulart SM, de Queiroz MELR, Neves AA, de Queiroz JH. Lowtemperature clean-up method for the determination of pyrethroids in milk using gas chromatography with electron capture detection. Talanta. 2008;75(5):1320-3.

38. Liu YE, Huang LQ, Luo XJ, Tan XX, Huang CC, Corella PZ, et al. Determination of organophosphorus flame retardants in fish by freezinglipid precipitation, solid-phase extraction and gas chromatography-mass spectrometry. J Chromatogr A. 2018;1532:68-73.

39. Amirav A, Dagan S. A direct sample introduction device for mass spectrometry studies and gas chromatography mass spectrometry analyses. Eur Mass Spectrom. 1997;3(2):105-11.

40. Cajka T, Mastovska K, Lehotay SJ, Hajslova J. Use of automated direct sample introduction with analyte protectants in the GC-MS analysis of pesticide residues. J Sep Sci. 2005;28(9-10):1048-60.

41. de Koning S, Lach G, Linkerhagner M, Loscher R, Tablack PH, Brinkman UAT. Trace-level determination of pesticides in food using difficult matrix introduction-gas chromatography-time-offlight mass spectrometry. J Chromatogr A. 2003;1008(2):247-52.
42. Norli HR, Christiansen AL, Stuveseth K. Analysis of non-cleaned QuEChERS extracts for the determination of pesticide residues in fruit, vegetables and cereals by gas chromatography-tandem mass spectrometry. Food Addit Contam A. 2016;33(2):300-12.

43. Patel K, Fussell RJ, Goodall DM, Keely BJ. Analysis of pesticide residues in lettuce by large volume-difficult matrix introductiongas chromatography-time of flight-mass spectrometry (LV-DMIGC-TOF-MS). Analyst. 2003;128(10):1228-31.

44. Mastovska K, Dorweiler KJ, Lehotay SJ, Wegscheid JS, Szpylka KA. Pesticide multiresidue analysis in cereal grains using modified QuEChERS method combined with automated direct sample introduction GC-TOFMS and UPLC-MS/MS techniques. J Agric Food Chem. 2010;58(10):5959-72.

45. Lehotay SJ, Lightfield AR, Harman-Fetcho JA, Donoghue DJ. Analysis of pesticide residues in eggs by direct sample introduction/gas chromatography/tandem mass spectrometry. J Agric Food Chem. 2001;49(10):4589-96.

46. Cacho JI, Campillo N, Vinas P, Hernandez-Cordoba M. Gas chromatography-mass spectrometry using microvial insert thermal desorption for the determination of BTEX in edible oils. RSC Adv. 2016;6(25):20886-91.

47. Edward A. Pfannkoch JAW, Jack R. Stuff. Elimination of non-volatile sample matrix components after GC injection using a thermal desorber and microvial Inserts. GERSTEL AppNote 4/2006. 2006.

48. Escher BI, Stapleton HM, Schymanski EL. Tracking complex mixtures of chemicals in our changing environment. Science. 2020;367(6476):388-92.

49. World Medical Association. Declaration of Helsinki: ethical principles for medical research involving human subjects. Jama-J Am Med Assoc. 2013;310(20):2191-4.

50. Smedes F. Determination of total lipid using non-chlorinated solvents. Analyst. 1999;124(11):1711-8.

51. Mayer P, Tolls J, Hermens L, Mackay D. Equilibrium sampling devices. Environ Sci Technol. 2003;37(9):184a-91a.

52. Matuszewski BK, Constanzer ML, Chavez-Eng CM. Strategies for the assessment of matrix effect in quantitative bioanalytical methods based on HPLC-MS/MS. Anal Chem. 2003;75(13):3019-30.

53. International conference on harmonization (ICH). In: Validation of analytical procedures: text and methodology Q2 (R1), ICH Secretariat, Geneva, Switzerland, 2005.

54. Ulrich N, Endo S, Brown TN, Watanabe N, Bronner G, Abraham MH, Goss KU. UFZ-LSER database v 3.2 [Internet], Leipzig, Germany, Helmholtz Centre for Environmental Research-UFZ. 2017 [accessed on 12.04.2020]. Available from http://www.ufz.de/lserd.

55. Chu SG, Covaci A, Jacobs W, Haraguchi K, Schepens P. Distribution of methyl sulfone metabolites of polychlorinated biphenyls and p,p '-DDE in human tissues. Environ Health Perspec. 2003;111(9):1222-7.

56. Pulkrabova J, Hradkova P, Hajslova J, Poustka J, Napravnikova M, Polacek V. Brominated flame retardants and other organochlorine pollutants in human adipose tissue samples from the Czech Republic. Environ Int. 2009;35(1):63-8.

57. Anastassiades M, Mastovska K, Lehotay SJ. Evaluation of analyte protectants to improve gas chromatographic analysis of pesticides. J Chromatogr A. 2003;1015(1-2):163-84.

58. Mastovska K, Lehotay SJ, Anastassiades M. Combination of analyte protectants to overcome matrix effects in routine $\mathrm{GC}$ analysis of pesticide residues in food matrixes. Anal Chem. 2005;77(24):8129-37.

59. Smedes F, van Vliet LA, Booij K. Multi-ratio equilibrium passive sampling method to estimate accessible and pore water concentrations of polycyclic aromatic hydrocarbons and polychlorinated biphenyls in sediment. Environ Sci Technol. 2013;47(1):510-7.

Publisher's note Springer Nature remains neutral with regard to jurisdictional claims in published maps and institutional affiliations. 